\title{
Boris Groys' Theory of Equal Rights in Aesthetics
}

\author{
Shijia Tang (Corresponding author) \\ School of Humanities, Southwest Jiaotong University \\ Chengdu, Sichuan, China \\ E-mail: 379781520@qq.com
}

Received: April 11, $2021 \quad$ Accepted: April 28, $2021 \quad$ Published: May 6, 2021

doi:10.5296/ijch.v8i1.18521ＵRL: https://doi.org/10.5296/ijch.v8i1.18521

\begin{abstract}
The concept of aesthetic equality was put forward by Groys, one of the important contemporary art theorists and critics, against the background of the decline of multiculturalism and the emergence of the drawbacks of postmodernism. This concept is mainly aimed at the overcorrection of postmodernism, which regards the confrontation with mainstream culture and traditional values as a problem of political correctness. It refers to the equality of aesthetic judgment and aesthetic choice. Aesthetic value judgment can not be evaluated according to the commercial value in the market circulation, nor can it be evaluated only according to the cultural value in the art history, let alone whether it conforms to or resists the mainstream culture, it should be judged according to its directivity to the infinite possibility of the absence of image and art. According to Groys, aesthetic equality is not only an expression of artistic autonomy, but also an expression of artistic power. Different from other theorists' discussion of artistic autonomy in the framework of self-discipline or heteronomy, he regards it as a force of resistance and liberation, the contemporary phenomenon of political aestheticization and the politicization of aesthetics all show the function of this power.
\end{abstract}

Keywords: artistic power, autonomy, aesthetic equality

\section{Equal Rights in Aesthetic Choice and Judgment}

Whether different aesthetic forms have equal status, whether there are advantages and disadvantages between different civilizations, whether art has the ability to resist oppression, and whether it has its own strength have been the central issues of cultural research. Groys put forward a concept of equal power in aesthetics in view of these problems, which mainly reflected in two aspects: one is equal power in aesthetic choice and judgment; the other is aesthetics as the power of striving for equality. 
Aesthetic choice and aesthetic judgment are related to the cognitive level and value orientation of aesthetic subject. Whether it is out of the reflection, confrontation or transcendence of reality, it involves class, race, nationality, age, gender and other issues to a certain extent. In human history, the aesthetic preferences of the holders of power and wealth are usually regarded as legitimate, correct and valuable, at present the most influential, rebellious and critical postmodernist trend of thought subverted this convention to some degree. Its emergence has won the legitimacy of existence for those marginalized cultures and aesthetic forms that rejected by the mainstream. Postmodernist scholars such as Foucault, Derrida and Deleuze usually took the difference principle as a way to explore political philosophy and cultural theory, through disenchantment of the social power structure, they trace back to the complex dynamics of the system and try to provide a practical transformation plan and to challenge cultural hegemony with diversity and heterogeneity, abandon the universality and singleness of mainstream culture (Gang Luo \& Xiangyu Liu, 2000:198). The aesthetic equality of postmodernism is to empower the marginal, the powerless, the minority, the weak, the experimental and the temporary culture.

As a result, today's art institutions are still regarded as a kind of privileged, elite and mysterious power institutions, which are doubted and distrusted by more and more people and art practitioners(Groys,2015:36). For a long time, art museums, repository, and archives have been regarded as the authority of choice, what is art and what kind of art works and artists deserve to be exhibited and recorded are defined by very few experts and insiders in these institutions, and this definition process is considered by the public to be esoteric and difficult to understand. Therefore, for the early avant-garde art, the confrontation with art institutions is equivalent to the confrontation with an aesthetic standard, hence many pioneering modernist schools, such as Impressionism, Fauvism and Cubism came into being. Today, when postmodernism is deeply rooted among the people, art institutions have been irrefutably disenchanted. There are endless voices about transcending, deconstructing and even abolishing the boundaries created by such art institutions. They believe that contemporary art needs complete freedom and participation in real life(Groys,2015:36), people should and can take back aesthetic autonomy. From the public's point of view, the traditional aesthetic demands represented by art institutions seem to be out of date and out of touch. The audience obviously more agree with and welcome the aesthetic concepts and preferences produced by contemporary media, contemporary art also shows an interest in following the entertainment media and mass communication, and the recognition of art institutions is no longer their ultimate pursuit, having a certain degree of exposure and visibility on various platforms, being widely accepted by the public has become their main goal. Of course, in the process of "participating in real life", many contemporary artists have also played a certain role in public communication and social and political life through this way, however, according to Groys, to have good liquidity means to have a certain commercial nature, he believes that the protest of contemporary art and cultural studies against art institutions and orthodox aesthetic tastes, is no longer an act of pursuing aesthetic equality as the early avant-garde art pursued. On the contrary, it stabilizes and establishes the prevailing cultural taste through this resistance (Groys, 2015: 36). 
The formation of post-modernist aesthetic taste is caused by the market in Groys' opinion, and its direct source is the globalization of information, media and entertainment market and the expansion of this market from $1970 \mathrm{~s}$ to $1990 \mathrm{~s}$ (Groys, 2015: 203). This kind of market expansion produces and supplies various and varied goods and concepts, and therefore provides an opportunity for the diversified and differentiated discourse and politics to be concerned and understood (Groys, 2015: 203). But it also leads to the collusion between multicultural criticism or politics of difference culture and the pluralism of cultural market, this kind of relationship weakens the strength of post-modern culture itself, and also reduces its effect against authority or mainstream.

Groys believes that the aesthetic taste of postmodernism is undoubtedly very inclusive, very open, and even truly democratic (Groys, 2015: 203), but it frequently questioned the so-called "closed" community, order, class, tradition and cultural identity formed in the early and long period of human society, the rejection of universality, normality, monotony and abstinence, as well as the tendency of taking pluralism and difference as a political right, show that it is not absolutely inclusive and democratic at this level. Because it presupposes an aesthetic preference, that is, an aesthetic preference for heterogeneity, cross-border and mixing, although this difference in cultural politics is not intended to oppose and compete for the status of mainstream culture (Gang Luo \& Xiangyu Liu,2000:198), or deliberately do something unconventional to impress others, there is no doubt that the concept of attitude has replaced the concept of times and become a standard of attitude. The aesthetic choice of postmodernism is gradually changing the particularity into another universality.

Groys believes that art itself has a kind of independent resistance, which is not used to decorate the existence of other external forces, whether they are used for oppression or liberation. His concept of aesthetic equality has a different logic from postmodernism. "The structure of lacking or even rejecting any aesthetic judgment" is the real aesthetic equality (Groys, 2015: 27).

\section{Aesthetics as a Force for Equal Rights}

Before analyzing the antagonistic power of art, we need to briefly discuss the relationship between art and politics. Although they have always been closely related, whether the "artistic power" proposed by Groys can be regarded as a political power still needs to be differentiated and analysed. There are two main perspectives of political aesthetics, namely, the analysis of "the aesthetic power contained in the political phenomenon and operation" and "the emphasis on political function in literature and aesthetics"(Pan Liyong, Zhang HuiWang, 2014).

Literature and art as a means of political operation is a long-standing tradition of human society. First of all, from the perspective of leaders and politicians, the art of persuasion, that is, rhetoric, plays an important role in politics. The Athenians regard it as the real and highest political art. In Athens, there is even a special worship of Peito, the goddess in charge of persuasion (Hannah Arendt, 2016: 103); correspondingly, in the pre Qin period of China, lobbying, a kind of activity in which strategists traveled all over the world to persuade the monarchs of various vassals to adopt their political ideas, also emphasized the skills of 
persuasion and the role of rhetoric; in modern political life, speech is still an important way for politicians to publicize political views, show their political positions, and obtain public attention and support. In addition to rhetoric, the image-building of leaders also plays an important role in political life. In the authority theory of Weber, the charismatic authority, that is, the leader's personal charm, as the legitimacy source of the government under his rule, is widely used in political activities. Leaders are often expected to show higher moral standards and energy beyond ordinary people. They seem to be the embodiment of justice, courage and selflessness, and become the symbolic existence of the savior, so they have strong cohesion and appeal. Obviously, aesthetics plays a legendary and symbolic role in the process of image-building. Secondly, from the perspective of political structure and social conception, the conception of ideal society and the method of governing the country also has certain aesthetic characteristics in some cases, for example, the idea of Utopia, the social ideal of "Great Harmony in the world (天下大同)" in Chinese Confucianism, and the social idea of "Sparse Population in a Small Country (小国寊民)" in Taoism. Both loose social organizations and complete social systems have certain aesthetic qualities.

It is inseparable that the role of art in conveying political stance and ideology has been emphasized and applied. For example, the Chinese Confucian tradition of "Poetic Education (诗教)" and "ceremonial and music civilization (礼乐)" emphasizes the social value function of literature and art. Poetry, courtesy and music can not only improve people's moral cultivation and cognitive level, help people express their intentions reasonably and properly in political and diplomatic occasions, but also can criticize society and interfere with reality to a certain extent. Another example is the application of socialist realistic aesthetic principles in socialist countries. The Constitution of the Soviet Writers Association directly requires that "artists should describe reality realistically and historically from the revolutionary development of reality; at the same time, the authenticity and historical concreteness of artistic description must be combined with the task of ideologically reforming and educating the working people with the socialist spirit" (Jiezhi Wang, 2012: 01).

Different from the political aesthetics under normal circumstances mentioned above, Groys discusses the relationship between art and politics from the internal similarity between them. He extended Hegel's theory that the pursuit of recognition is the fundamental driving force of human conflict and evolution, and pointed out that the two fields of art and politics were initially connected in a basic direction, that is, "strive for recognition(Groys, 2015:28)". The goal of this struggle is not only that a certain political group comes to power and the interests of the class it represents are met, and a certain genres of art or artist has won mainstream recognition or has a place in the art market, that is, an individual or collective is recognized by the public. But in the process of pursuing legitimacy, "all kinds of interests and interests of all people will eventually be given equal rights, including all forms and artistic procedures (Groys, 2015: 28)".

Hannah Arendt once pointed out that the task and ultimate intention of politics is to defend life in the broadest sense, to make individuals themselves and to protect people from the interference of politics (Hannah Arendt, 2016: 108). The meaning of politics is freedom (Hannah Arendt, 2016: 103). The meaning of Groys' aesthetic equality is similar to this. In his 
view, the early avant-garde art has opened an infinite horizon for the art form, and abstract graphics, industrial products, daily life, human body, behavior, concepts, have all been included in the art field. Art is no longer limited to craftsmanship, so the intelligence and transcendence of art works begin to be valued and emphasized, and all kinds of new art forms have been recognized which was only gave to "masterpieces" in the past. This process of equal artistic practice has become more and more routine in the 20th century. Kitsch, entertainment and popular culture have gained equal seats in the traditional high-level artistic context. The definition of art is infinitely extended, and the audience's acceptance, understanding and expectation are correspondingly promoted and expanded. This is the same as the intention of contemporary political inclusion and helping the weak in politics and economy. According to Groys, this kind of aesthetic equality is a necessary condition for political equality (Groys, 2015: 29). Because in reality, the inequality of various image symbols is imposed by external inequality, only when the minority and marginal groups are no longer removed from the culture at the very start and are no longer degraded by the order of aesthetic values can their political efforts to be accepted and realized. But it should be noted that in the process of striving for equality, it is understandable that postmodernism takes subversion and deconstruction of orthodox, mainstream and authoritative art forms and cultural symbols as a means of artistic innovation. However, we must realize that the confronted part provides reference coordinates for confrontational behavior, and every deconstructed result may become a new reference object. Classics and traditions are still very important and they deserve their position.

But the equal aesthetic value of all art forms and media does not mean that there is no longer a standard of art (Groys, 2015: 30). Groys pointed out that contemporary art is different from traditional art, the masterpieces created by artists before the French Revolution should be able to visualize the concept of abstract truth and beauty, they refer to the sacred truth in the "vertical" dimension, while the masterpieces in modern and contemporary art refer to the infinite image sequence in the "horizontal" dimension, therefore, the aesthetic equal rights logic in modern and contemporary works of art has become an important measure of its value. Because the equal rights logic behind the efforts made by politics and art to win recognition has been well known and these efforts have been recognized, the concepts of freedom, democracy and equality are almost as natural as sunshine, air and water. As a result, people have become accustomed to various endless political activities and artistic thoughts. The novelty of artistic works or artistic ideas, like the postmodern aesthetic choices mentioned above, has been acquiesced as a customary practice in contemporary times. Therefore, the seriousness and explosiveness of the efforts made by art and politics have been reduced to a certain extent. Groys pointed out that this does not mean that the effort of art to strive for recognition and equality have reached the logical end. Although the formal aesthetic equality has been basically achieved, the substantive aesthetic equality needs to be confirmed repeatedly. And good art is the art that still affirms that all images are equal in form under the condition of actual inequality. For example, Kandinsky's abstract paintings, Duchamp's ready-made art and Warhol's popular cultural images, their impact does not come from the uniqueness of their contents or the subtlety of their skills, but from their reference to images with infinite diversity and equal status, they are just examples of these possibilities. Their 
enlightening and exemplary functions make them have the value beyond the current historical context, that is to say, aesthetic equality is a hint, which is dynamic and critical, and responds accordingly with the historical environment. Groys' aesthetic equality is uneven equality, flowing value and pluralistic meaning. Therefore, we can say that the "artistic power" mentioned by Groys comes from the autonomy of art, the distance between art and society makes it possible to reflect and criticize economy, society, culture, politics and history, while the affirmation of aesthetic equality by art guarantees its autonomy (Groys, 2015: 31).

\section{The Strategy of Aesthetic Equal Rights}

There are many ways in which art affirms and achieves aesthetic equality. Here are two prominent forms in Groys' discourse to illustrate the aesthetic equal rights strategy in contemporary art.

Groys pointed out that in the contemporary era of popular culture and cultural globalization, artists have two typical reactions to it. One is to graft the images produced by popular culture into their own local culture, to some extent, it helps them to get rid of the regional limitations of local culture and reflection on it through this way. For example, the political pop art. Political Pop is an art trend in some socialist countries from 1970s to 1990s. They often use pop's artistic expression to combine western commercial symbols with socialist political images and present them with some absurd and humorous effect. Different from the classical pop art in Europe and the United States, classical pop art mainly takes the current pop culture as the main body of expression, and it can often turns the popular daily elements into works of art in the hall of elegance. The main body of political pop is the cultural memory related to socialism, but it can often turns the lofty and serious symbolic elements into a fashion trend (Xianting Li, 2000: 310-311). For example, Chinese contemporary artist Wang Guangyi (王 广义)'s "Great Criticism" (1990-2007) series combines the characters of workers, peasants and soldiers and their body language with the trademarks of western modern commodities such as Coca-Cola, Pepsi-Cola, Gucci and Dior, and makes it produce a kind of Cultural Revolution propaganda poster effect. This series can be interpreted as a double criticism of "Utopia" and "fetishism"(Xian Zhou, 2018: Vol. 5, 01), as well as the spirit of the times in China in the 1990s, which is in a period of great change (Guangyao Zhu, Jialin Cao, 2020: 07), but generally it refers to daily life and modern commercial culture under the grand historical background. 

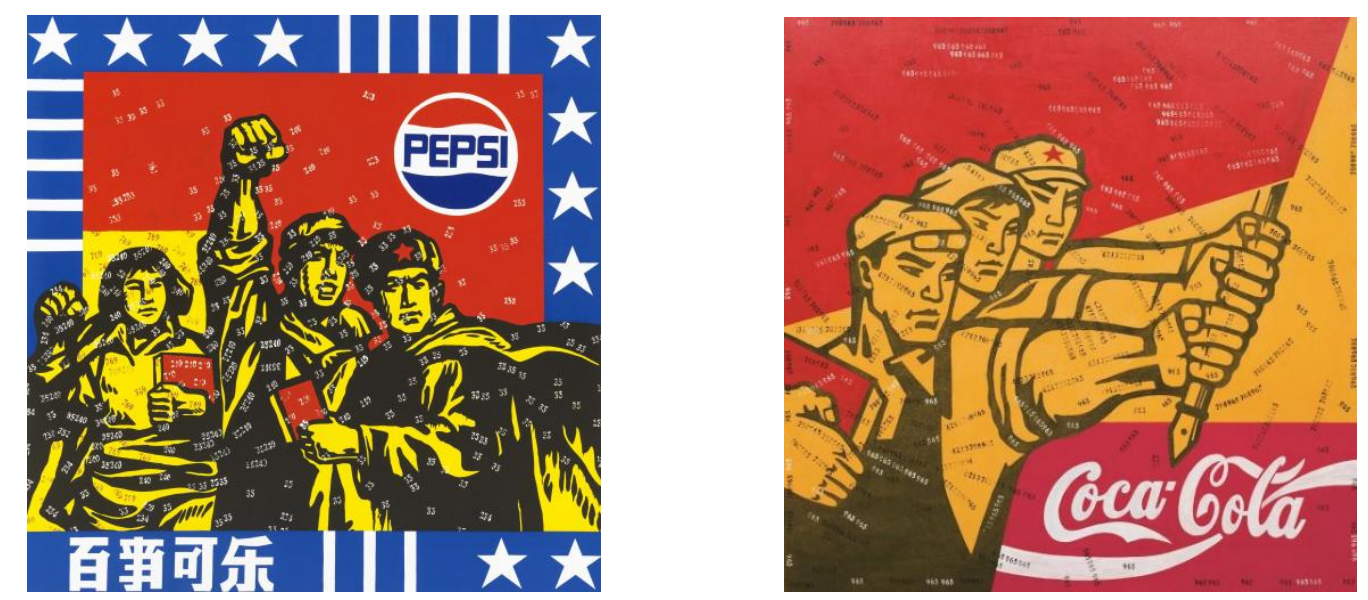

Figure $1 \& 2$. Tow of Wang Guangyi's “Great Criticism” Series

The other reaction is to introduce the regional and national characteristics which are neglected and weakened by popular culture into the international perspective. Art works that imply the cultural origin and with regional color, to a certain extent, resisted the aesthetic control of media norms. For example, Chinese contemporary young artist Zi Peng (訾鹏) inherited Wang Guangyi's creative logic, his series of art works "Jade" use the painting skills of oil painting to draw typical western foods such as hamburger, ice cream and cream cake, classic foreign cartoon characters such as Mickey Mouse, Popeye and Hello Kitty, and famous pop art symbols of contemporary western artists such as Jeff Koons' dog and Damien Hirst's skull, and the most important is that they are painted with the texture of jade, at the same time the scenery of traditional Chinese ink landscape painting is used to show the texture details of jade. Although the form and content of these paintings are western, the core is the presentation of Chinese jade culture and traditional ink landscape, in this artistic form, the series indicates the loss of "gentleman spirit (君子精神)" in the rapidly changing contemporary Chinese society.
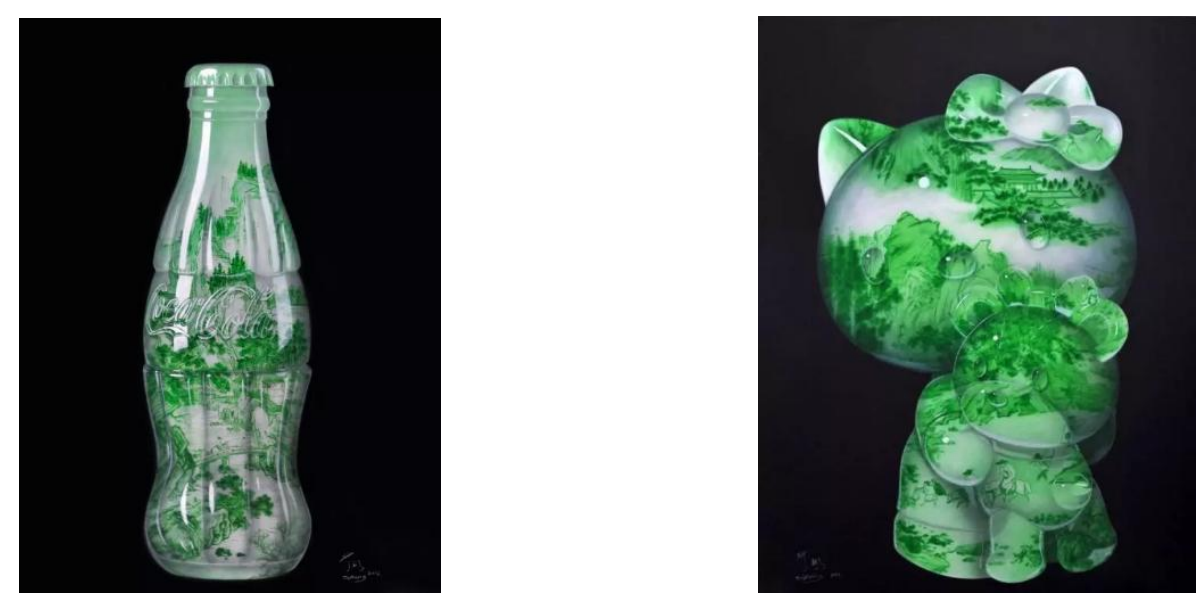

Figure $3 \& 4$. Tow of Zi Peng's “Jade” Series 
The intention of these two ways seems to be quite different, one emphasizes breaking the cultural closeness, the other emphasizes the recognition of the national culture it represents, but in essence, they all refer to the absent, excluded or ignored part of the image in the cultural field, and all point to the aesthetic equality, a utopian aesthetic ideal (Groys, 2015: $31)$.

In conclusion we can find that on the one hand, Groys inherited the theory and critical methods of Frankfurt school, on the other hand, he questioned the objectivity of cultural studies, and showed a tendency to "grand narrative". For Groys, art should not be regarded as a craft merely participating in circulation, pleasing the audience or as a pleasurable occupation, nor should art merely stay in the irony and rebellion against reality, what is important in art is to show the spirit of freedom independent of various ideologies, and to show concern for human beings' living conditions and cultural values (Xianting Li, 2000: $381)$.

\section{References}

Arendt, H. (2016). The Promise of Politics. Shanghai: Shanghai People's Publishing House.

Groys, B. (2015). Art Power. Taiwan: Artists.

Li, X. T. (2000). It's not Art that Matters. Nanjing: Jiangsu Fine Arts Publishing House.

Luo, G., \& Liu, X. Y. (Eds.). (2000). Reading Books of Cultural Studies. Beijing: China Social Science Press.

Pan, L. Y., \& Zhang, H. (2014). Wang Anshi's Political Aesthetics and its Significance of the Times. Journal of Shaanxi Normal University (Philosophy and Social Sciences Edition), 43(05).

Wang, J. Z. (2012). The Theoretical Course of "Socialist Realism" in China. Journal of College of Arts of Nanjing Normal University, (01).

Zhou, X. (2018). Wang Guangyi's Chinese pop art iconology - Taking the series of great criticism: Coca Cola as the analysis object. Academic Monthly, 5(01).

Zhu, G. Y., \& Cao, J. L. (2020). Rational return after the new trend - On Wang Guangyi's great criticism. Art evaluation, (07).

\section{Copyrights}

Copyright for this article is retained by the author(s), with first publication rights granted to the journal.

This is an open-access article distributed under the terms and conditions of the Creative Commons Attribution license (http://creativecommons.org/licenses/by/4.0/) 